\title{
Spatio Temporal Influence of Isoflavonoids on Bacterial Diversity in the Soybean Rhizosphere
}

\author{
Laura J. White, ${ }^{1}$ Karuppaiyan Jothibasu, ${ }^{2}$ R. Neil Reese, ${ }^{1}$ Volker S. Brözel, ${ }^{1,3}$ and Senthil Subramanian ${ }^{1,2}$ \\ ${ }^{1}$ Department of Biology and Microbiology, ${ }^{2}$ Department of Plant Science, South Dakota State University, Brookings, SD 57007, \\ U.S.A.; ${ }^{3}$ Department of Microbiology and Plant Pathology, University of Pretoria, Pretoria 0004, South Africa
}

Submitted 26 August 2014. Accepted 30 September 2014.

High bacterial density and diversity near plant roots has been attributed to rhizodeposit compounds that serve as both energy sources and signal molecules. However, it is unclear if and how specific rhizodeposit compounds influence bacterial diversity. We silenced the biosynthesis of isoflavonoids, a major component of soybean rhizodeposits, using RNA interference in hairy-root composite plants, and examined changes in rhizosphere bacteriome diversity. We used successive sonication to isolate soil fractions from different rhizosphere zones at two different time points and analyzed denaturing gradient gel electrophoresis profiles of $16 \mathrm{~S}$ ribosomal RNA gene amplicons. Extensive diversity analysis of the resulting spatio temporal profiles of soybean bacterial communities indicated that, indeed, isoflavonoids significantly influenced soybean rhizosphere bacterial diversity. Our results also suggested a temporal gradient effect of rhizodeposit isoflavonoids on the rhizosphere. However, the hairy-root transformation process itself significantly altered rhizosphere bacterial diversity, necessitating appropriate additional controls. Gene silencing in hairy-root composite plants combined with successive sonication is a useful tool to determine the spatio temporal effect of specific rhizodeposit compounds on rhizosphere microbial communities.

Pioneering microbiology studies by L. Hiltner in the early 1900s showed that the highest microbial density in soils occurs very close to plant roots (Hinsinger and Marschner 2006). For example, a four- to fivefold increase in CFU was observed in root-surface scrapings as compared with soil samples $0.5 \mathrm{~cm}$ away from the roots (Clark 1940). Such changes are attributed to the rich carbon energy sources provided by the plant. Indeed, plants release, on average, 10 to $15 \%$ (Jones et al. 2009) of their photosynthetic assimilates into the rhizosphere, a process called rhizodeposition (Dennis et al. 2010). These rhizodeposits originate from sloughed off root border and root border-like cells from root tips, active root exudation, and cell lysis. Rhizodeposits are composed of sugars, amino acids, organic acids, fatty acids, proteins, ions, secondary metabolites, mucilage,

Corresponding authors: V. S. Brözel; E-mail: volker.brozel@sdstate.edu; S. Subramanian; E-mail: senthil.subramanian@sdstate.edu

* The $\boldsymbol{e}$-Xtra logo stands for "electronic extra" and indicates that seven supplementary figures, two supplementary tables, and one supplementary data file are published online.

(C) 2015 The American Phytopathological Society water, and miscellaneous carbon-containing compounds (Bais et al. 2006; Dennis et al. 2010).

Significant evidence accumulated over the years indicates that the composition of root microbial communities is influenced, in large part, by the plant species and its developmental stage (Micallef et al. 2009; Mougel et al. 2006; Weisskopf et al. 2006). Indeed, an intricate coevolution of plants and rhizosphere microbial communities was suggested by the observation that resident plants or their root exudates are capable of maintaining the biomass and diversity of soil fungal communities to a much greater extent than nonresident or introduced plants (Broeckling et al. 2008). This is supported by the observation that invasive weeds have the ability to significantly influence native rhizosphere microbial communities to exert their dominance in new environments (Inderjit et al. 2006). Therefore, it is clear that components of rhizodeposits significantly influence the composition and activity of rhizosphere microbial communities.

It is not well-understood which rhizodeposit compounds recruit or influence which groups of microbes and how. An effective approach is to examine microbial associations with plant mutants deficient in the biosynthesis and rhizodeposition of specific groups of compounds (Prithiviraj et al. 2005; Rudrappa et al. 2008). It is worth noting that composition of rhizodeposits varies substantially among different plant species (Czarnota et al. 2003; Warembourg et al. 2003). Therefore, studies using model plant species might not reveal the roles of species-specific rhizodeposit compounds (e.g., isoflavonoids that are legume-specific compounds). This demands the development of an efficient system to generate plant materials with altered rhizodeposit composition as well as reproducible methods to isolate and examine rhizosphere microbes. We and others have previously used RNA interference (RNAi) in hairy-root composite plants to elucidate the role of flavonoids in specific root-microbe interactions (Oger et al. 1997; Wasson et al. 2006; Zhang et al. 2009). For example, we identified that isoflavonoids in soybean are essential for interaction with the symbiont Bradyrhizobium japonicum (Subramanian et al. 2006) and resistance against the root-rot pathogen Phytophthora sojae (Subramanian et al. 2005). These results unequivocally demonstrated the crucial roles of isoflavonoids in the interaction of soybeans with these microbes and also established that RNAi in hairy-root composite plants can be used to effectively modify rhizodeposit compositions. We used RNAi in hairy-root composite plants to silence isoflavonoid biosynthesis, used successive sonication steps to reproducibly isolate microbial communities with different affinities to the roots, and demonstrate using denaturing gradient gel electrophoresis (DGGE) analyses that root isoflavonoids significantly influence soybean rhizosphere microbial communities. 


\section{RESULTS}

Root surface preparations and analysis of bacterial diversity.

We used an RNAi construct against isoflavone synthase (IFS) to generate isoflavonoid-deficient hairy-root composite plants as previously described (Collier et al. 2005; Subramanian et al. 2006). Consistent silencing of IFS genes in these roots and a significant reduction in root isoflavonoids were confirmed by quantitative polymerase chain reaction (PCR) and high-performance liquid chromatography analyses, respectively (Supplementary Fig. S1). We planted vector-transformed controls (VC) and IFS-RNAi (IFSi)-transformed composite plants in soil mixed from various soybean fields and harvested roots at 1 and 3 weeks postplanting (wpp) for root-surface preparations. These root-surface preparations, representing different rhizosphere zones, were collected through three successive sonication steps (Fig. 1). We hypothesized that the stronger the bacterial proximity or affinity to the roots, the stronger the physical force (i.e., sonication time) required to isolate them. Three successive sonication steps yielded the distal soil (DS), middle soil (MS), and proximal soil (PS) samples. We expected that the PS sample would represent the fraction that is very closely associated with the root surface, including bacterial biofilms. Bacterial communities in each of the samples were analyzed by DGGE profiling of $16 \mathrm{~S}$ ribosomal (r)RNA gene amplicons (V3 to V5 region). Dissimilarities between samples from different rhizosphere regions, different time points after planting, and root isoflavonoid content were compared through rigorous population diversity and statistical analyses.

\section{Distinct bacterial groups isolated} using differential sonication.

First, we tested to learn if bacterial communities obtained from different sonication times were reproducible, by comparing DS, MS, and PS samples from two independent experiments. Indeed, we obtained three distinct clusters of bacterial communities in a reproducible manner using different sonication times both at 1 and 3 wpp (Fig. 2, DS vs. MS vs. PS). Detrended correspondence analysis (DCA) using the decorana method in the R package vegan showed that the DS, MS, and PS samples had distinct profiles at both 1 and 3 wpp (Fig. 2A and C). The first two DCA axes explained approximately 65 to $70 \%$ of the variance. The difference among the DS, MS, and PS samples was statistically significant based on adonis, a nonparametric multivariate analysis of variance test using distance matrices at both 1 and 3 wpp $(P<0.05$, Bray-Curtis distance matrices). The same conclusion was obtained using constrained ordination analyses (capscale and constrained correspondence analysis; Supplementary Fig. S2). In agreement, hierarchical cluster analysis also placed samples from different rhizosphere zones into distinct branches (Fig. 2B and D). It is worth noting that in all these analyses, the profiles of distal rhizosphere zone samples were very distinct from those of middle and proximal zone samples. Such distinct separation suggests that successive sonication can reproducibly isolate distinct bacterial communities with increasing affinity or proximity to plant roots.

\section{Effect of time-in-soil on bacterial composition.}

Next, we examined if the length of time in the soybean field soil affected the composition of rhizosphere bacterial communities. We compared PS bacterial profiles between roots from 1 and 3 wpp plants in both VC and IFSi plants. Results from DCA indicated that, regardless of root genotype, samples obtained from 1 and 3 wpp were clearly different from one another, at least in the PS (Fig. 3A, E vs. L). The first two DCA axes explained approximately $73 \%$ of the variance. The effect of timein-soil was statistically significant in influencing bacterial community composition (adonis $P<0.05$, Bray-Curtis distance matrix). This conclusion was also supported by other constrained ordination analyses (Supplementary Fig. S3). Constrained axes explained approximately 90 to $95 \%$ of the variance between the 1 and 3 wpp samples. Consistently, hierarchical cluster analysis also showed that bacterial profiles of 1 and 3 wpp roots clustered in distinct branches (Fig. 3B). General diversity indices (Shannon, Simpson, and Inverse Simpson) were generally higher for samples obtained $3 \mathrm{wpp}$ compared with those obtained 1 wpp (Supplementary Fig. S4). In addition, there was no obvious pattern among the general diversity indices in the different rhizosphere zones at $1 \mathrm{wpp}$. Interestingly, the proximal rhizosphere zones had less diversity than the distal and middle zones at 3 wpp (Supplementary Fig. S5). It appears that the bacterial communities had established themselves at specific rhizosphere zones at $3 \mathrm{wpp}$ as compared with 1 wpp. Some bacteria likely utilized the extra time to drive out competitors while others needed specific bacteria present before they could thrive.

\section{Effect of isoflavonoids on bacterial composition in the rhizosphere.}

We also examined the effect of root isoflavonoid composition on bacterial community dissimilarities in the three rhizosphere zones. Results from DCA showed that VC and IFSi roots had clearly distinguishable bacterial profiles at both 1 and 3 wpp. However, at 1 wpp, the DS samples did not appear to show any significant difference between the two genotypes (Fig. 2A, VC DS vs. IFSi DS), whereas MS and PS samples from the two genotypes were well separated (Fig. 2A, VC PS vs. IFSi PS and VC MS vs. IFSi MS). In contrast, at $3 \mathrm{wpp}$, the two genotypes showed a significant difference in bacterial commu-

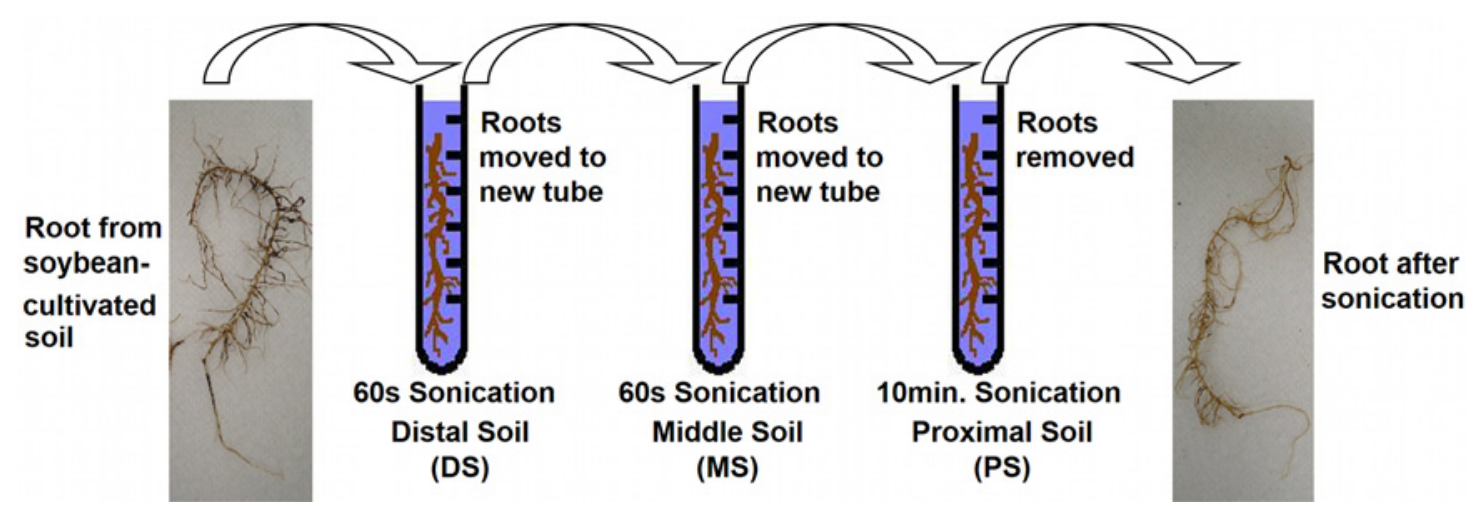

Fig. 1. Schematic indicating successive sonication steps used to isolate distal, middle, and proximal soil samples from soybean roots. Pictures of a soybean composite plant root before and after the three sonication steps are shown. 
nity composition in all three rhizosphere zones (Fig. 2C, VC DS vs. IFSi DS, VC MS vs. IFSi MS, and VC PS vs. IFSi PS). As above, additional constrained coordinate analyses clearly supported these conclusions. Hierarchical cluster analysis, on the other hand, indicated that, at $3 \mathrm{wpp}$, there was a clear separation of samples from VC and IFSi roots in each rhizosphere zone but not at 1 wpp. For example, we observed clear subbranching of VC and IFSi PS samples at 3 wpp (Fig. 2D), but no such separation was observed at $1 \mathrm{wpp}$. Therefore, by 3 wpp, isoflavonoids clearly exert a significant influence on microbial composition in all three rhizosphere zones examined. The effect of root genotype on bacterial community composition was statistically significant at $3 \mathrm{wpp}$ (adonis $P<0.05$, Bray-Curtis distance matrix).

Use of hairy-root composite plants

for rhizosphere microbiome studies.

Having established that, at $3 \mathrm{wpp}$, all three rhizosphere zones examined had significant differences in bacterial community composition between VC and IFSi roots, we performed a thorough analysis at this time point with multiple replicates obtained from at least three independent root-surface prepara- tions. Since the hairy-root composite plant generation is known to alter the physiology of roots, we also used another control, in which we generated "composite plants" without Agrobacterium rhizogenes infection. These plants underwent the same "transformation" procedure but produced adventitious roots from stem explants instead of transgenic hairy roots. Comparison of bacterial community composition between untransformed (UNR) and VC roots suggested that the hairyroot transformation procedure itself altered the microbiome of all three rhizosphere zones at $3 \mathrm{wpp}$. The bacterial profiles of transgenic VC roots and nontransgenic UNR roots were significantly different from each other in all three rhizosphere zones (Fig. 4A, C, and E, VC vs. UNR). Nevertheless, comparison of bacterial community composition between $\mathrm{VC}$ and IFSi roots indicated that reduced root isoflavone levels significantly influenced the microbiome of all three rhizosphere zones at 3 wpp (Fig. 4A, C, and E, VC vs. IFSi). The differences in each zone were statistically significant (adonis $P<0.01$, BrayCurtis distance matrix). Similar to the above comparisons, additional constrained correspondence analyses also pointed to the same conclusion (Supplementary Fig. S6). Hierarchical clustering yielded varying branches across the three rhizo-
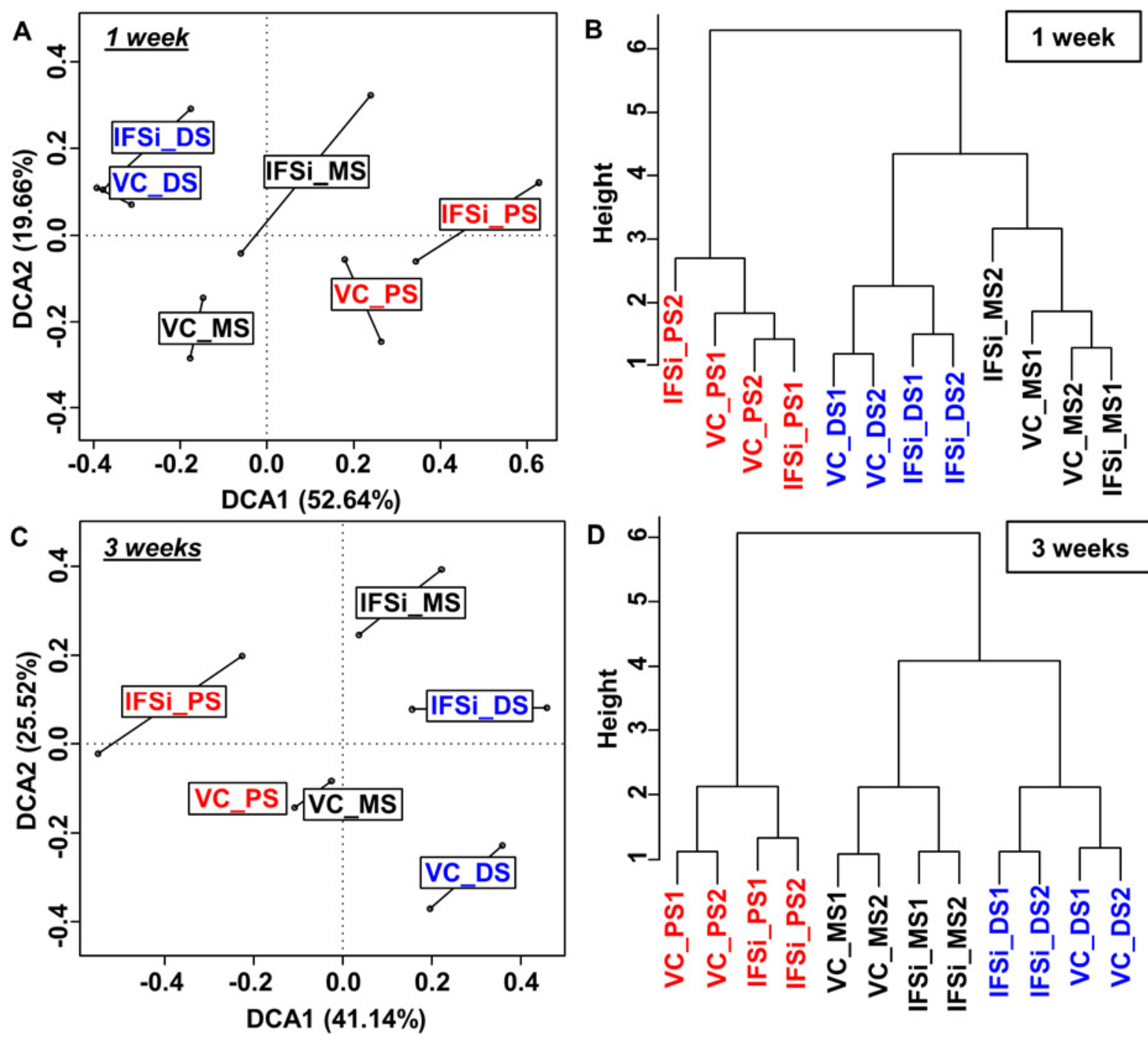

Fig. 2. A and C, Detrended correspondence analysis (DCA) plots showing the separation of distal, middle, and proximal soil (DS, MS, and PS, respectively) samples from vector-transformed controls (VC) and isoflavone synthase-RNA interference (IFSi) roots at 1 and 3 weeks after planting. DCA1 and DCA2 indicate the major axes of dissimilarity. Data points of the same sample type from two independent experiments are shown connected by a line. B and $\mathbf{D}$, Dendrograms showing hierarchical clustering of DS, MS, and PS samples from VC and IFSi roots at 1 and 3 weeks after planting. Numbers following the sample labels indicate the experiment from which they were obtained. 
sphere zones, presumably due to variation between independent root-surface preparations. The DS zone samples had two distinct branches, one with VC and the other with UNR and IFSi samples. The second branch had two major sub-branches enriched for either UNR or IFSi samples (Fig. 4B). The MS zone samples formed two distinct branches one for UNR and the other for VC. Four of the six IFSi samples had a distinct sub-branch closer to UNR samples, indicating clear differences between VC and IFSi samples (Fig. 4D). The PS zone samples also had two distinct branches but one with VC and the other with UNR and IFSi samples. The second branch had two major sub-branches dividing close to the origin. Each of these branches were enriched for either UNR or IFSi samples (Fig. 4F).

Our results indicate that i) isoflavonoid rhizodeposits significantly influence the microbiome of soybean rhizosphere, ii) differential sonication can be used to reproducibly isolate microbes in different rhizosphere zones, iii) a longer growth period of plants in the soil enables them to strongly influence the rhizosphere, and iv) the hairy-root composite process itself significantly influences the rhizosphere microbiome, necessitating additional controls when using this system to study the roles of specific rhizodeposit compounds in the rhizosphere.

\section{DISCUSSION}

A number of studies have identified the influence of plant genotype and the environment on the composition and diversity of rhizosphere microbiota (Bulgarelli et al. 2012; Gottel et al. 2011; Peiffer et al. 2013; Philippot et al. 2013). In addition, either the roles of specific compounds in rhizodeposits, the roles of specific cellular transport machinery on rhizosphere microbial diversity, or both have been investigated (Bais et al. 2006; Walker et al. 2003). In the latter case, the availability of genetic mutants impaired in biosynthesis and transport of specific rhizodeposit compounds has been crucial. For example, mutations in an Arabidopsis thaliana ABC-transporter gene, ABCG30 (resulting in increased exudation of phenolic acids and reduced exudation of sugars), caused significant changes in root microbial community structure as assayed by high-throughput sequencing of rRNA gene amplicons (Badri et al. 2008, 2009). This study revealed the association of a number of potentially beneficial bacteria with abcg30 mutant roots. Some rhizodeposit compounds are produced by nearly all plant species and these primarily serve as carbon sources (e.g., amino acids, sugars, and polysaccharides). In addition to these, there are a number of species-specific compounds that are likely to attract specific microbes that have the capacity to metabolize them as a carbon source or that might serve as signal molecules to specific rhizosphere microbes (e.g., isoflavonoids in soybean). Therefore, determining the roles of species-specific rhizodeposit compounds in shaping the microbial community is crucial for rhizosphere engineering. A major bottleneck in such approaches is the lack of a comprehensive collection of genetic mutants in all plant species. We used RNAi in hairy-root composite plants to overcome this bottleneck and manipulate root isoflavonoid composition and, thus, rhizodeposit isoflavonoid composition. This method is adaptable to a wide variety of dicot species. The $A$. rhizogenes strain $\mathrm{K} 599$ has a broad host range, and composite plants ready to plant in soil can be obtained in 2 to 4 weeks, using the ex vitro composite plant generation method. It should, however, be noted that the majority of monocots cannot be transformed using A. rhizogenes, which makes this approach limited to dicots. In addition, the method produces composite plants with transgenic roots and untransformed shoots. Therefore, shoots still have an active biosynthesis pathway and compounds that are transported from the shoot to the root and exuded or deposited are less likely to be affected unless specific transporters (if known) are silenced. Also, although RNAi silencing is a very successful procedure, plant roots may still produce inconsistent, though miniscule, levels of rhizodeposit compounds that may still impact the rhizosphere bacterial communities. This may result in additional variation amongst samples, as seen in the IFSi samples from all three rhizosphere zones (Fig. 4). Finally, we noticed that the hairy-root transformation process itself can alter the microbiome and, therefore, relevant controls are necessary to make proper conclusions and interpretations. Nevertheless, the method appears to be wellsuited to study the effect of specific rhizodeposit compounds on rhizosphere microbes in many plant species that lack a comprehensive mutant collection. When combined with quantitative and high-resolution bacterial profiling methods such as pyrosequencing, some of these variations can be directly correlated to the level of silencing to better interpret the results.
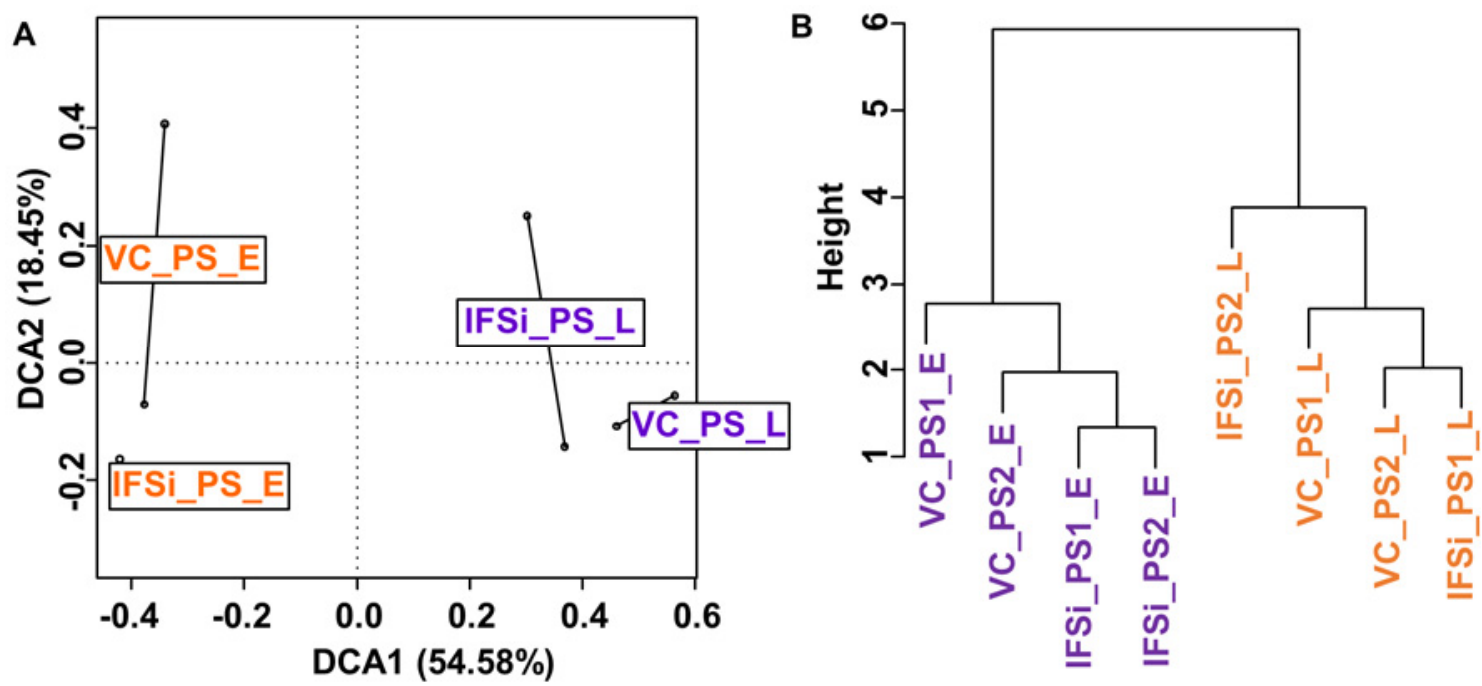

Fig. 3. A, A Detrended correspondence analysis (DCA) plot showing the separation of proximal soil (PS) samples from vector-transformed control (VC) and isoflavone synthase-RNA interference (IFSi) roots 1 and 3 weeks after planting (E and L, respectively). DCA1 and DCA2 indicate the major axes of dissimilarity. Data points of the same sample type from two independent experiments are shown connected by a line. B, A dendrogram showing the hierarchical clustering of PS samples. Numbers following the sample labels indicate the experiment from which they were obtained. 
Previous studies used sonication to either separate rhizosphere soil from nonrhizosphere soil or to isolate one region of the rhizosphere (Bulgarelli et al. 2012; Doi 2007). We used successive sonication to reproducibly isolate different soil
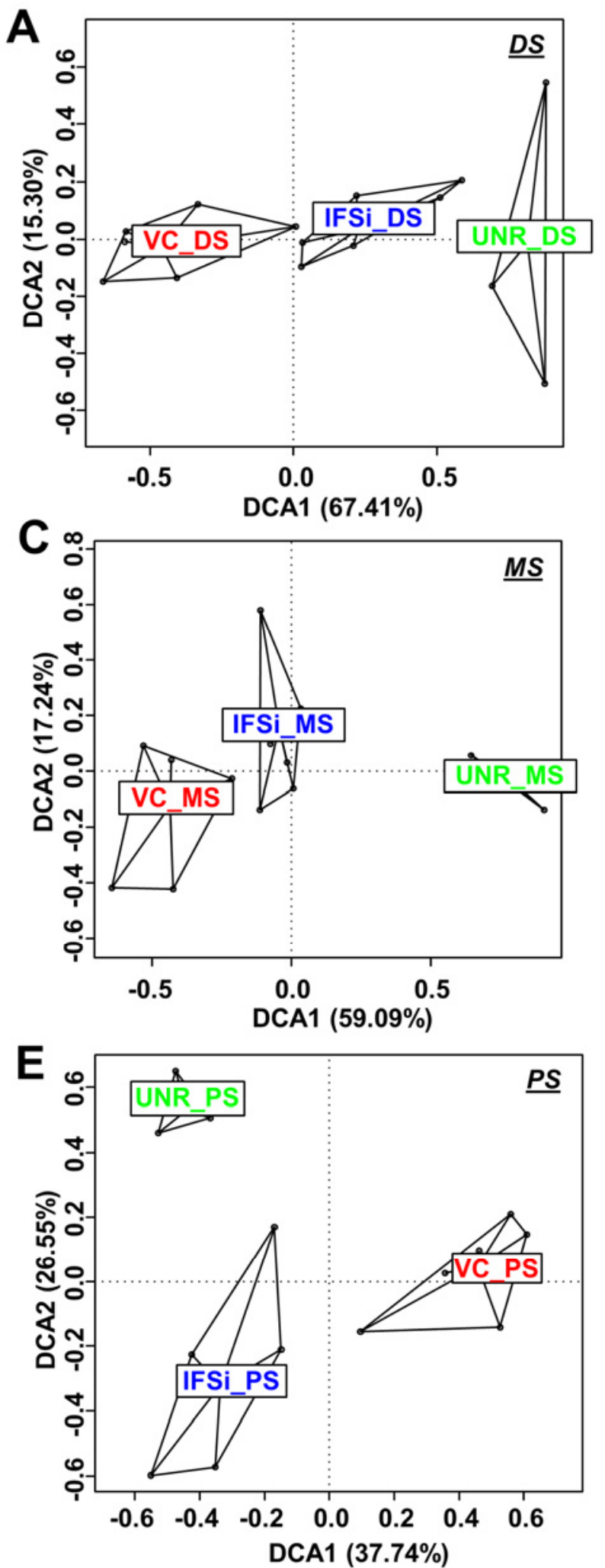

fractions with specific bacterial composition. We defined these as distal, middle, and proximal soil fractions for convenience. Isolating cultivable bacterial species from these fractions and subsequently examining their colonization will enable us to
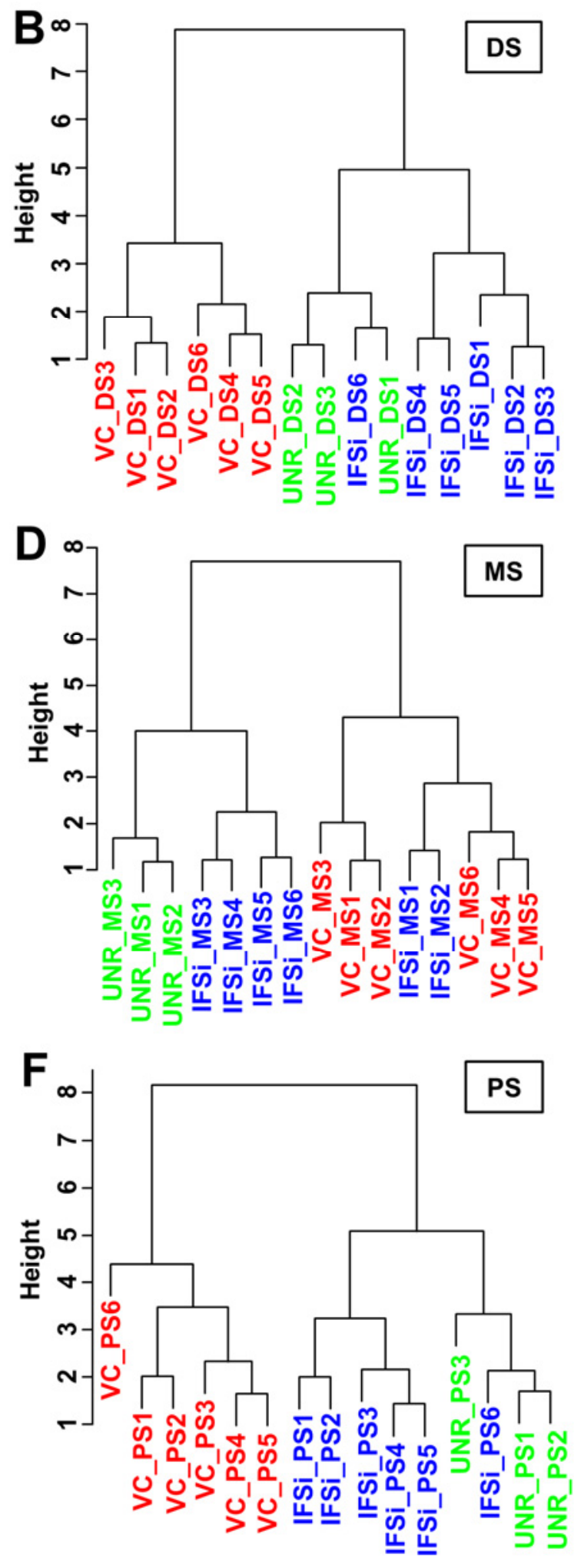

Fig. 4. A, C, and E, Detrended correspondence analysis (DCA) plots showing the separation of distal, middle, and proximal soil (DS, MS, and PS, respectively) samples from vector-transformed control (VC), isoflavone synthase-RNA interference (IFSi), and untransformed (UNR) roots 3 weeks after planting. DCA1 and DCA2 indicate the major axes of dissimilarity. Data points of the same sample type from two independent experiments are shown connected by lines. B, D, and F, Dendrograms showing the hierarchical clustering of DS, MS, and PS samples from VC, IFSi, and UNR roots 3 weeks after planting. Numbers following the sample labels indicate the experiment from which they were obtained. 
validate their spatial localization in the rhizosphere. Nevertheless, reproducible isolation of similar bacterial communities from these preparations suggested that the same strength of sonication isolated the same set of bacteria from the roots. In addition, longer presence of roots in the soil was required to influence bacterial communities in soils with least affinity to the roots. It is conceivable that rhizodeposits can attract or dissuade microorganisms but only at a limited distance. For example, rhizodeposit compounds might form a gradient merely due to physical diffusion or utilization by microbes in the proximal soil.

Finally, our results indicate that root flavonoids significantly influenced bacterial community composition in the rhizosphere in a spatio temporal manner. Isoflavonoids have been implicated in nonspecific defense against plant pathogens (Dixon 2001; Dixon et al. 2002). Isoflavonoids also regulate nod genes in rhizobia bacteria, specifically $B$. japonicum (Kosslak et al. 1987). Additionally, compared with sugars, amino acids, and organic acids present in rhizodeposits, isoflavonoids (and other secondary metabolites) are species-specific and are more likely to recruit unique microbial communities. Silencing of isoflavonoid biosynthesis in the roots did not significantly influence other metabolites in the phenylpropanoid pathway, except the accumulation of liquiritigenin (the substrate of IFS), $p$-hydroxy benzoic acid, coumaric acid, and $p$-hydroxybenzaldehyde (Lozovaya et al. 2007; Subramanian et al. 2006) (data not shown). We cannot exclude the possibility that a small proportion of the changes in root bacterial profiles could be due to these relatively small changes in nontarget phenylpropanoids. We also considered other approaches, such as the use of RNAi to silence components of flavonoid exudation machinery and the use of adsorbents to prevent rhizodeposit isoflavonoids from reaching rhizosphere microbes. However, rhizodeposition of isoflavonoids occurs through mechanisms other than root exudation as well, e.g., root border cells (Hawes et al. 2000). Therefore, silencing components of root exudation machinery (e.g., ABC transporters [Brechenmacher et al. 2009; Sugiyama et al. 2007]) might not result in efficient depletion of isoflavonoids in rhizodeposits. Similarly, the use of adsorbents might disrupt quorum signals between bacteria and cause nonspecific modifications in root-surface microbial communities and exert unpredicted, indirect impacts on nontarget organisms, including the plant producing the flavonoids (Hassan and Mathesius 2012). Subsequent identification of specific bacterial phylotypes that are different between VC and IFSi roots through culture-dependent and sequence-based culture-independent methods (e.g., pyrosequencing) will reveal the specific influence of rhizodeposit isoflavonoids on bacterial communities in the soil. Identifying bacteria impacted by isoflavonoids will allow us to better understand how these rhizodeposits influence the rhizosphere and what benefits, if any, soybean derives from rhizodeposit isoflavonoids. This knowledge could be applied to agricultural pursuits to promote plant growth and increase food production in a sustainable and environmentally friendly manner by altering relevant rhizosphere bacterial communities.

\section{Conclusion.}

Results from our experiments clearly demonstrate that root isoflavonoids significantly influence rhizosphere bacterial community composition. Identifying bacterial communities influenced by isoflavonoids in the soybean rhizosphere through pyrosequencing and/or culture-based experiments would reveal information that would i) improve our scientific understanding of communication between plant and rhizosphere microbes, and ii) ultimately aid better rhizosphere management and sustainable agriculture.

\section{MATERIALS AND METHODS}

\section{Plant materials, soil, and growth conditions.}

Soybean (Glycine max cv. Williams 82) seeds were surfacesterilized via submersion and agitation in a $10 \%$ bleach solution for $4 \mathrm{~min}$, followed by rinsing with distilled water six to seven times and submersion and agitation in a $70 \%$ ethanol solution for $2 \mathrm{~min}$ and again rinsing with distilled water six to seven times. The seeds were then sown in 4-in pots filled with an autoclaved vermiculite/perlite (1:3) mixture and were watered with Hoagland solution (Hoagland and Arnon 1950; Supplementary Table S1). Growth conditions were as follows: $50 \%$ relative humidity, $16 \mathrm{~h}$ of light, $8 \mathrm{~h}$ of dark, approximately $25^{\circ} \mathrm{C}$ day and $20^{\circ} \mathrm{C}$ night temperatures.

The soil used to isolate rhizosphere bacteria was obtained by pooling approximately 200 samples from agricultural fields with a history of soybean cultivation from South Dakota and western Minnesota submitted to the South Dakota State University (SDSU) soil-testing laboratory. The samples were cleared of plant materials, were mixed well, and were stored at $4{ }^{\circ} \mathrm{C}$ until further use ("soybean field soil"). Physical and chemical properties of the soil samples are listed in Supplementary Table S2.

\section{DNA vectors, and plant transformation.}

The DNA vectors (control and IFSi constructs) have been previously described (Subramanian et al. 2005). Fourteen-dayold seedlings (possessing their first trifoliate leaves) were used for composite plant generation as described previously (Collier et al. 2005), except that Agrobacterium rhizogenes cultures (VC or IFSi) used for transformation were cultured for 16 to $20 \mathrm{~h}$ in Luria Bertani broth supplemented with $50 \mathrm{mg}$ of kanamycin per liter at $30^{\circ} \mathrm{C}$, and then, were centrifuged at $3,500 \times$ $g$ for $8 \mathrm{~min}$ at $4^{\circ} \mathrm{C}$ and resuspended in nitrogen-free plant nutrient solution. The plants were grown under previously described conditions (Subramanian et al. 2006). After 3 weeks, successfully transformed roots were identified by green fluorescent protein epifluorescence via a fluorescein isothiocyanate filter, using an Olympus SZX16 Epi-Fluorescence Stereo Microscope, marked with "Tough-Tags" (Diversified Biotech), and were subsequently planted in soybean field soil.

\section{Isolation of rhizosphere soil.}

To obtain rhizosphere samples, plants were removed from soil after 1 and 3 weeks and roots were subjected to three consecutive sonications. A Fisher Scientific FS20 model sonicator (input: $117 \mathrm{~V}^{-} 50$ to $60 \mathrm{~Hz} 1 \phi$, output: $70 \mathrm{~W} 42 \mathrm{kHz} \pm 6 \%$ ) was used for this experiment. The harvested roots were first shaken gently in a still pool of distilled (d) $\mathrm{H}_{2} \mathrm{O}$ to remove larger soil particles. Next, they were severed from the plant and were placed in separate $15-\mathrm{ml}$ tubes with $10 \mathrm{ml}$ of phosphate buffered saline Tween20 (PBST). These tubes were subjected to a 60-s sonication to collect DS from the roots. The roots were then moved to new $15-\mathrm{ml}$ centrifuge tubes with 10 $\mathrm{ml}$ of fresh PBST and were subjected to another 60-s sonication to collect MS from the plant roots. After that the roots were relocated to new $15-\mathrm{ml}$ tubes containing $10 \mathrm{ml}$ of fresh PBST and were subjected to a 10-min sonication to collect PS from the roots. The material released from roots was harvested by centrifugation $(5,000 \times g$ for $10 \mathrm{~min}$ or $4,500 \times g$ for 15 $\mathrm{min})$. To address concerns that sonication might disrupt bacterial cells and result in DNA contamination across the PS, MS, and DS zones we subjected Escherichia coli K12, a strain well-known for its relatively weak cell-wall properties, to our successive sonication method and evaluated differences in $\mathrm{CFU}$ and found no significant difference between control and cell suspensions subjected to $10 \mathrm{~min}$ of sonication, suggesting 
that there was no significant disruption of bacterial cells (Supplementary Fig. S7).

\section{DNA isolation, PCR, and DGGE.}

DNA was extracted from 0.09 to $0.47 \mathrm{~g}$ of harvested rhizosphere materials using the PowerSoil DNA isolation kit (MO BIO Laboratories, Inc.), following the manufacturer's protocol.

The 16S rRNA variable regions V3 to V5 were amplified using a Gene Amp PCR System 9700 model thermocycler machine in a $30-\mu \mathrm{l}$ reaction mixture $(0.2 \mu \mathrm{l} \mathrm{Taq}$ DNA polymerase (Promega/Invitrogen), $6 \mu \mathrm{l}$ of PCR buffer, $0.15 \mu \mathrm{l}$ of dNTP (10 $\mathrm{mM}$, Promega), $1.8 \mu \mathrm{l}$ of $\mathrm{MgCl}_{2}(25 \mathrm{mM}), 1.2 \mu \mathrm{l}$ of forward primer $(0.01 \mathrm{mM}), 1.2 \mu \mathrm{l}$ of reverse primer $(0.01 \mathrm{mM}), 18.95$ $\mu \mathrm{l}$ of Nanopure $\mathrm{H}_{2} \mathrm{O}, 0.5 \mu \mathrm{l}$ (approximately100 $\mathrm{ng}$ ) of template DNA). PCR parameters were as follows: preliminary denaturation at $94^{\circ} \mathrm{C}$ for $5 \mathrm{~min},\left(94^{\circ} \mathrm{C}\right.$ for $30 \mathrm{~s}, 56^{\circ} \mathrm{C}$ for $45 \mathrm{~s}, 72^{\circ} \mathrm{C}$ for $1 \mathrm{~min}$ ) for 30 cycles, final elongation at $72^{\circ} \mathrm{C}$ for $7 \mathrm{~min}$, and $10^{\circ} \mathrm{C}$ indefinitely for storage. Forward primer F357 containing a 5' 40-base GC- clamp (Brons and van Ems 2008; Muyzer et al. 1993) and reverse primer R907 (Teske et al. 1996) were used for DNA amplification in this experiment.

PCR products were subjected to denaturing gradient gel electrophoresis as described previously (Muyzer et al. 1993). PCR product $(40 \mu \mathrm{l})$ was resolved using a 35 to $70 \%$ denaturant gradient gel in $1.25 \times$ Tris-acetate-EDTA buffer in a DCode System (BioRAD). Electrophoresis was executed at $60^{\circ} \mathrm{C}$ at 20 $\mathrm{V}$ until DNA moved through the cap gel, and then, at $70 \mathrm{~V}$ for $16 \mathrm{~h}$. Gels were stained for $20 \mathrm{~min}$ in SYBR gold (30 $\mu \mathrm{l}$ in 300 $\mathrm{ml}$ of $\mathrm{dH}_{2} \mathrm{O}$ [Invitrogen]), and images were captured with UV transillumination (BioRAD Chemidoc XRS).

\section{DGGE gel image analysis.}

Quantity One (BioRAD) software was used to capture the intensity of the data and ascertain and subtract the amount of background noise within each DGGE image as previously described (Rettedal 2011). The resulting quantitative data were then rounded to the nearest whole number in Microsoft Excel (Supplementary Data File) and were subsequently analyzed further using the vegan package (Oksanen et al. 2013) of $R$ software (R Core Team 2013) (version 3.0.2). General diversity indices (Shannon, Simpson, and Inverse-Simpson) were obtained by executing the respective commands and then plotting the indices against one another. Unconstrained ordination analyses were accomplished by first implementing the detrended correspondence analysis commands (using "iweigh=-1," "iresc=4," and "ira=0" to downweigh rare species, execute four rescaling cycles, and perform a detrended analysis using the decorana method) and, then, plotting the data (only displaying the "sites"). Nonparametric multivariate analysis of variance for partitioning distance matrices among sources of variation was performed using adonis. Linear models were tested for each variable and their statistical significance determined. Due to the non-normal distribution of the community data, it was standardized in R (via the center_scale command with scale = FALSE to only subtract the mean), and all resulting values were increased by 1,000 and were subject to a $\log 10$ transformation prior to hierarchical clustering. Cluster analyses were performed on the normalized, logarithmically transformed data by calculating Euclidean dissimilarity matrices (using the vegdist and hclust commands) and plotting the data.

\section{ACKNOWLEDGMENTS}

This research was funded by the South Dakota Agricultural Experiment Station and the South Dakota Soybean Research and Promotion Council. We acknowledge use of the SDSU-Functional Genomics Core Facility, supported by National Science Foundation Experimental Program to Stim- ulate Competitive Research grant number 0091948, the South Dakota 2010 Drought Initiative, and the South Dakota Agricultural Experiment Station. We thank R. Gelderman (SDSU) for providing soil samples, M. Hildreth (SDSU) for providing the sonicator used in this project, and the two anonymous reviewers for valuable feedback and guidance.

\section{LITERATURE CITED}

Badri, D. V., Loyola-Vargas, V. M., Broeckling, C. D., De-la-Pena, C., Jasinski, M., Santelia, D., Martinoia, E., Sumner, L. W., Banta, L. M., Stermitz, F., and Vivanco, J. M. 2008. Altered profile of secondary metabolites in the root exudates of Arabidopsis ATP-binding cassette transporter mutants. Plant Physiol. 146:762-771.

Badri, D. V., Quintana, N., El Kassis, E. G., Kim, H. K., Choi, Y. H., Sugiyama, A., Verpoorte, R., Martinoia, E., Manter, D. K., and Vivanco, J. M. 2009. An ABC transporter mutation alters root exudation of phytochemicals that provoke an overhaul of natural soil microbiota. Plant Physiol. 151:2006-2017.

Bais, H. P., Weir, T. L., Perry, L. G., Gilroy, S., and Vivanco, J. M. 2006. The role of root exudates in rhizosphere interations with plants and other organisms. Ann. Rev. Plant Biol. 57:233-266.

Brechenmacher, L., Lee, J., Sachdev, S., Song, Z., Nguyen, T. H., Joshi, T., Oehrle, N., Libault, M., Mooney, B., Xu, D., Cooper, B., and Stacey, G. 2009. Establishment of a protein reference map for soybean root hair cells. Plant Physiol. 149:670-682.

Broeckling, C. D., Broz, A. K., Bergelson, J., Manter, D. K., and Vivanco, J. M. 2008. Root exudates regulate soil fungal community composition and diversity. Appl. Environ. Microbiol. 74:738-744.

Brons, J. K., and van Ems, J. D. 2008. Analysis of bacterial communities in soil by use of denaturing gradient gel electrophoresis and clone libraries, as influenced by different reverse primers. Appl. Environ. Microbiol. 74:2717-2727.

Bulgarelli, D., Rott, M., Schlaeppi, K., van Themaat, E. V. L., Ahmadinejad, N., Assenza, F., Rauf, P., Huettel, B., Reinhardt, R., Schmelzer, E., Peplies, J., Gloeckner, F. O., Amann, R., Eickhorst, T., and SchulzeLefert, P. 2012. Revealing structure and assembly cues for Arabidopsis root-inhabiting bacterial microbiota. Nature 488:91-95.

Clark, F. E. 1940. Notes on types of bacteria associated with plant roots. T Kansas Acad. Sci. 43:75-84.

Collier, R., Fuchs, B., Walter, N., Kevin Lutke, W., and Taylor, C. G. 2005 Ex vitro composite plants: An inexpensive, rapid method for root biology. Plant J. 43:449-457.

Czarnota, M. A., Rimando, A. M., and Weston, L. A. 2003. Evaluation of root exudates of seven sorghum accessions. J. Chem. Ecol. 29:20732083.

Dennis, P. G., Miller, A. J., and Hirsch, P. R. 2010. Are root exudates more important than other sources of rhizodeposits in structuring rhizosphere bacterial communities? FEMS (Fed. Eur. Microbiol. Soc.) Microbiol. Ecol. 72:313-327.

Dixon, R. A. 2001. Natural products and plant disease resistance. Nature 411:843-847.

Dixon, R. A., Achnine, L., Kota, P., Liu, C.-J., Reddy, M. S. S., and Wang, L. 2002. The phenylpropanoid pathway and plant defence-A genomics perspective. Mol. Plant Pathol. 3:371-390.

Doi, T, Hagiwara,Y., Abe J, and Morita S. 2007. Analysis of rhizosphere bacteria of rice cultivated in Andosol lowland and upland fields using molecular biological methods. Plant Root 1:66-74.

Gottel, N. R., Castro, H. F., Kerley, M., Yang, Z., Pelletier, D. A., Podar, M., Karpinets, T., Uberbacher, E., Tuskan, G. A., Vilgalys, R., Doktycz, M. J., and Schadt, C. W. 2011. Distinct microbial communities within the endosphere and rhizosphere of populus deltoides roots across contrasting soil types. Appl. Environ. Microbiol. 77:5934-5944.

Hassan, S., and Mathesius, U. 2012. The role of flavonoids in root-rhizosphere signalling: Opportunities and challenges for improving plantmicrobe interactions. J. Exp. Bot. 63:3429-3444.

Hawes, M. C., Gunawardena, U., Miyasaka, S., and Zhao, X. 2000. The role of root border cells in plant defense. Trends Plant Sci 5:128-133.

Hinsinger, P., and Marschner, P. 2006. Rhizosphere-Perspectives and challenges-A tribute to Lorenz Hiltner 12-17 September 2004, Munich, Germany. Plant Soil 283:vii-viii.

Hoagland, D. R., and Arnon, D. I. 1950. The water-culture method for growing plants without soil. California Agricultural Experiment Station. College of Agriculture, University of California, Berkeley, CA, U.S.A.

Inderjit, Callaway, R. M., and Vivanco, J. M. 2006. Can plant biochemistry contribute to understanding of invasion ecology? Trends Plant Sci. 11:574-580.

Jones, D., Nguyen, C., and Finlay, R. 2009. Carbon flow in the rhizosphere: Carbon trading at the soil-root interface. Plant Soil 321:5-33.

Kosslak, R. M., Bookland, R., Barkei, J., Paaren, H. E., and Appelbaum, 
E. R. 1987. Induction of Bradyrhizobium japonicum common nod genes by isoflavones isolated from Glycine max. Proc. Natl. Acad. Sci. U.S.A. 84:7428-7432

Lozovaya, V., Lygin, A., Zernova, O., Ulanov, A., Li, S., Hartman, G., and Widholm, J. 2007. Modification of phenolic metabolism in soybean hairy roots through down regulation of chalcone synthase or isoflavone synthase. Planta 225:665-679.

Micallef, S. A., Channer, S., Shiaris, M. P., and Colon-Carmona, A. 2009 Plant age and genotype impact the progression of bacterial community succession in the Arabidopsis rhizosphere. Plant Signal Behav. 4:777-780.

Mougel, C., Offre, P., Ranjard, L., Corberand, T., Gamalero, E., Robin, C. and Lemanceau, P. 2006. Dynamic of the genetic structure of bacterial and fungal communities at different developmental stages of Medicago truncatula Gaertn. cv. Jemalong line J5. New Phytol. 170:165-175.

Muyzer, G., Dewaal, E.C., and Uitterlinden, A.G. 1993. Profiling of complex microbial populations by denaturing gradient gel-electrophoresis analysis of polymerase chain reaction-amplified genes coding for $16 \mathrm{~s}$ ribosomal-RNA. Appl. Environ. Microbiol. 59:695-700.

Oger, P., Petit, A., and Dessaux, Y. 1997. Genetically engineered plants producing opines alter their biological environment. Nat. Biotechnol. 15:369-372.

Oksanen, J., Blanchet, G. F., Kindt, R., Legendre, P., Minchin, P. R., O’Hara, R. B., Simpson, G. L., Solymos, P., Stevens, M. H. H., and Wagner, H. 2013. vegan: Community Ecology Package. R package version 2.0-9. Published online.

Peiffer, J. A., Spor, A., Koren, O., Jin, Z., Tringe, S. G., Dangl, J. L., Buckler E. S., and Ley, R. E. 2013. Diversity and heritability of the maize rhizosphere microbiome under field conditions. Proc. Natl. Acad. Sci. U.S.A. 110:6548-6553.

Philippot, L., Raaijmakers, J. M., Lemanceau, P., and van der Putten, W. H. 2013. Going back to the roots: The microbial ecology of the rhizosphere. Nat. Rev. Micro. 11:789-799.

Prithiviraj, B., Bais, H. P., Weir, T., Suresh, B., Najarro, E. H., Dayakar, B. V., Schweizer, H. P., and Vivanco, J. M. 2005. Down regulation of virulence factors of Pseudomonas aeruginosa by salicylic acid attenuates its virulence on Arabidopsis thaliana and Caenorhabditis elegans. Infect. Immun. 73:5319-5328.

R Core Team. 2013. R: A Language and Environment for Statistical Computing. R Foundation for Statistical Computing, Vienna, Austria.
Rettedal, E. A. 2011. Methods to collect and analyze accurate representations of bacterial communities. Ph.D. dissertation, LB2386.R37. South Dakota State University, Brookings, SD, U.S.A.

Rudrappa, T., Czymmek, K. J., Pare, P. W., and Bais, H. P. 2008. Rootsecreted malic acid recruits beneficial soil bacteria. Plant Physiol. 148:1547-1556.

Subramanian, S., Graham, M. Y., Yu, O., and Graham, T. L. 2005. RNA interference of soybean isoflavone synthase genes leads to silencing in tissues distal to the transformation site and to enhanced susceptibility to Phytophthora sojae. Plant Physiol. 137:1345-1353.

Subramanian, S., Stacey, G., and Yu, O. 2006. Endogenous isoflavones are essential for the establishment of symbiosis between soybean and Bradyrhizobium japonicum. Plant J. 48:261-273.

Sugiyama, A., Shitan, N., and Yazaki, K. 2007. Involvement of a soybean ATP-binding cassette-type transporter in the secretion of genistein, a signal flavonoid in legume-rhizobium symbiosis. Plant Physiol 144:2000-2008

Teske, A., Wawer, C., Muyzer, G., and Ramsing, N. B. 1996. Distribution of sulfate-reducing bacteria in a stratified fjord (Mariager fjord, Denmark) as evaluated by most-probable-number counts and denaturing gradient gel electrophoresis of PCR-amplified ribosomal DNA fragments. Appl. Environ. Microbiol. 62:1405-1415.

Walker, T. S., Bais, H. P., Grotewold, E., and Vivanco, J. M. 2003. Root exudation and rhizosphere biology. Plant Physiol. 132:44-51.

Warembourg, F. R., Roumet, C., and Lafont, F. 2003. Differences in rhizosphere carbon-partitioning among plant species of different families. Plant Soil 256:347-357.

Wasson, A. P., Pellerone, F. I., and Mathesius, U. 2006. Silencing the flavonoid pathway in Medicago truncatula inhibits root nodule formation and prevents auxin transport regulation by rhizobia. Plant Cell 18:16171629.

Weisskopf, L., Abou-Mansour, E., Fromin, N., Tomasi, N., Santelia, D., Edelkott, I., Neumann, G., Aragno, M., Tabacchi, R., and Martinoia, E. 2006. White lupin has developed a complex strategy to limit microbial degradation of secreted citrate required for phosphate acquisition. Plant Cell Environ. 29:919-927.

Zhang, J., Subramanian, S., Stacey, G., and Yu, O. 2009. Flavones and flavonols play distinct critical roles during nodulation of Medicago truncatula by Sinorhizobium meliloti. Plant J. 57:171-183. 